\title{
A split-screen electronic messaging system for Apple II computers
}

\author{
DENIZ ERGENER and A. RODNEY WELLENS \\ University of Miami, Coral Gables, Florida
}

\begin{abstract}
A method is described for configuring an Apple II+ or Apple IIe computer to create a multiuser, multiwindowed, electronic messaging system for use in computer-mediated communication research.
\end{abstract}

With the increased availability of local and long-distance computer networks, there has been an increasing amount of interest regarding the social psychological aspects of computer-mediated communication (Chapanis, 1972; Johansen, 1984; Johansen, Vallee, \& Spangler, 1979; Short, Williams, \& Christie, 1976). The effects of interactive text-based messaging upon group decision making, productivity, participation rates, leadership, coalition formation, and other social behaviors have been studied using a variety of multiuser systems. This paper describes a method by which a relatively inexpensive single-user microcomputer (an Apple II+ or Apple IIe) can be configured to emulate a multiwindowed, multiuser messaging system typically restricted to more expensive computer systems.

Kiesler, Siegel, and McGuire (1984) and Murrel (1983) described computer conferencing experiments that utilize multiuser systems whose software divides each user's terminal screen into several parts and allows messages from different people to appear simultaneously and scroll independently. The ability of users to monitor messages as they are being entered into the system (rather than waiting for completed messages to be delivered to the screen) allows participants to interrupt each other and may bring about a greater feeling of social "immediacy." Our goal was to create a similar system for studying two-person interactions using relatively inexpensive equipment immediately available to many experimenters. The software can be used either to support a stand-alone messaging system for computer-mediated communication research or to act as the front end of a more elaborate on-line, textbased data acquisition and analysis sytem. It is one of several subsystems recently added to a multimedia laboratory for social interaction research (Wellens, 1979).

\section{HARDWARE COMPONENTS}

The system consists of an Apple IIe or Apple II+ computer equipped with two Apple II Super Serial cards, one

This project was supported in part by a University of Miami Research and Sponsored Programs Summer Award in Business and the Social Sciences awarded to the second author. The author's mailing address is: Department of Psychology, University of Miami, P. O. Box 248185, Coral Gables, FL 33124.
Videx Videoterm 80-column display card (replacing the standard 80-column card within the Apple IIe), four monochrome television monitors and two remote keyboard terminals (e.g., Synertek KTM-3 terminals) capable of serial communications. Three of the television monitors are connected in parallel to the video output pin of the Videx 80-column video display card placed in Slot 3 of the Apple. The Videx card is used to store character information and provide the split-screen video display viewed by users. Each keyboard is connected via an RS232 cable to one of the serial cards placed in Slots 2 and 4 of the Apple. One remote monitor and keyboard is placed before each subject, and the third monitor is used by the experimenter to follow the text exchanged between subjects. The fourth monitor is connected to the Apple's normal 40-column video output connector and can be used to monitor other programs that can be run simultaneously on the Apple.

\section{SOFTWARE DESCRIPTION}

An assembly language program was written that treats the Videx 80-column card as an external device for displaying text received from either of the keyboard terminals connected to the two serial ports. When an entry is made on either keyboard, the serial card to which it is connected generates an interrupt signal within the Apple. The assembly program detects the interrupt, polls the status register of each serial port to decide which card sent the interrupt, and then receives the character sent from the card's data buffer. The program then branches to a subroutine that POKEs the character in either the top or bottom half of the $2 \mathrm{~K}$ video display buffer of the Videx card. The program also POKEs a flag to a memory location within the Apple, designating which port received the message, and POKEs the character sent to an adjacent memory location. This information can be used by other programs which can be run simultaneously to calculate response latencies, compute message lengths, or perform other real-time tasks.

The 80-column screen generated by the Videx card is divided in half by a horizontal line (created by using a graphics character available within the Videx character set) that remains at center screen. Up to 11 lines of text 
may be displayed both above and below the center line. All text received from the keyboard connected to Slot 2 is displayed above the center line (upper window), and all text received from the keyboard connected to Slot 4 is displayed below the center line (lower window). Both windows have automatic wrap-around and line-feed capabilities. When messages exceed 11 lines, each window is capable of scrolling independently; the oldest line scrolls off the top of the window with new lines added to the bottom of the window. Each window has its own cursor that can be backspaced for making corrections by using either the "backspace" or "delete" key on the remote keyboard terminals. Line feeds are automatically generated whenever a "return" or "enter" key is struck.

A short BASIC program boots the system, sets the communication parameters on the serial cards (i.e., adjusts baud rate, word length, stop bits, and parity to be compatible with the remote terminals being used), loads and then runs the assembly language program. The BASIC program erases itself after performing these functions. The assembly program that is left running takes up less than $1 \mathrm{~K}$ of memory space within the Apple and resides within memory locations reserved for the Apple's second high resolution graphics screen. It is written as a "background" program that remains essentially invisible to other programs that may be subsequently loaded and run simultaneously.

\section{PROGRAM AVAILABILITY}

An annotated source code listing of the assembly language program, the auto-boot BASIC program, and a short BASIC demonstration program is provided in the Appendix.

\section{REFERENCES}

Chapanis, A. (1972). Studies of interactive communication: The effects of four communication modes on the behavior of teams during cooperative problem-solving. Human Factors, 14, 487-509.

JoHANSEN, R. (1984). Teleconferencing and beyond: Communications in the office of the future. New York: McGraw-Hill.

Johansen, R., VAlleE, J., \& SPANGLER, K. (1979). Electronic meetings: Technical alternatives and social choices. Reading, MA: Addison-Wesley.

KIESLER, S., Siegel, J., \& MCGuire, T. (1984). Social psychological aspects of computer-mediated communication. American Psychologist, 39, 1123-1134.

MURREL, S. (1983, October). Computer communication system design affects group communication. In A. R. Wellens (Chair), Microcomputers in social interaction research. Symposium conducted at the Society of Southeastern Social Psychologists, Winston-Salem, NC.

Short, J., Williams, E., \& Christie, B. (1976). The social psychology of telecommunications. New York: Wiley \& Sons.

WeLleNS, A. R. (1979). An interactive television laboratory for the study of social interaction. Joumal of Nonverbal Behavior, 4, 119-122.

\section{Appendix}

THE FOLLOWING IS AN ASSEMBLY LANGUAGE PROGRAM THAT TREATS A VIDEX 80-COLUMN CARD AS AN EXTERNAL DEVICE FOR DISPLAYING TEXT RECEIVED FROM TWO KEYBOARD TERMINALS CONNECTED TO AN APPLE IIE OR II+ COMPUTER VIA TWO SUPER SERIAL CARDS. THE PROGRAM DISPLAYS TEXT RECEIVED FROM KEYBOARD ONE WITHIN THE TOP HALF OF THE 80-COLUMN SCREEN AND DISPLAYS TEXT RECEIVED FROM KEYBOARD TWO WITHIN THE BOTTOM HALF OF THE SCREEN. EACH HALF OF THE SCREEN SCROLLS INDEPENDENTLY. OTHER PROGRAMS MAY BE RUN SIMUL TANEOUSLY WITH THIS PROGRAM TO MONITOR MESSAGING BEHAVIOR. THESE PROGRAMS CAN PEEK AT LOCATION 17017 TO DETERMINE WHICH KEYBOARD WAS THE LAST TO BE ACTIVE (1 OR 2) AND PEEK TO LOCATION 17018 TO DETERMINE THE LAST CHARACTER RECEIVED (ASCII 0-255).

SOURCE FILE: COMM IIE

\begin{tabular}{|c|c|c|}
\hline $\begin{array}{l}\text { C08B: } \\
\text { CO8A: } \\
\text { C089: } \\
\text { C088: } \\
\text { 03FE: } \\
\text { O3FF: } \\
\text { 0020: } \\
\text { C040: } \\
0045: \\
0007: \\
0002: \\
\text { 0020: } \\
\text { 04FB: } \\
\text { 057B: } \\
\text { 05FB } \\
\text { OS78: } \\
\text { 06F8: } \\
\text { 07F8: }\end{array}$ & $\begin{array}{l}1 \text { CONTROL } \\
2 \text { COMMAND } \\
3 \text { STATUS } \\
4 \text { DATA } \\
5 \text { IRQ1 } \\
6 \text { IRQ2 } \\
7 \text { SLOT } \\
8 \text { SLOT2 } \\
9 \text { ACC } \\
10 \text { CUR } \\
11 \text { SEPR } \\
12 \text { SP } \\
13 \text { BASEH } \\
14 \text { HOR } \\
15 \text { VER } \\
16 \text { BYTE } \\
17 \text { NO } \\
18 \text { MSLOT }\end{array}$ & 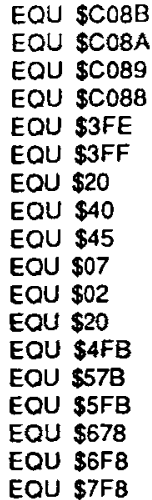 \\
\hline
\end{tabular}

NEXT OBJECT FILE NAME IS COMM IIE.OBJO

\begin{tabular}{|c|c|c|}
\hline 4000: & $\begin{array}{l}19 \\
20\end{array}$ & ORG $\$ 4000$ \\
\hline 4000: & $\begin{array}{l}21 \\
22\end{array}$ & - INITIALIZATION ROUTINE \\
\hline
\end{tabular}


4000:A9 36

$4002: 8 D A B C 0$

4005:8D CB CO

4008:A9 69

400A:8D AA C0

400D:8D CA CO

4010:A9 4E

4012:8D FE 03

4015:A9 40

4017:8D FF 03

401A:58

401B:20 7B 40

401E:20 09 C8

4021: $\mathrm{A9}$ OA

4023:8D BO CO

4026:A9 20

4028:8D B1 CO

402B:A9 07

402D:AE 4D 41

4030:AC 4E 41

4033:201242

4036:AE 1042

4039:AC 1142

403C:20 1242

403F:A2 00

$\triangle 041$ AO OC

4043:A9 02

4045:20 1242

4048: E8

4049:EO 50

404B:D0 F6

404D:60

$404 \mathrm{E}$

$404 E$

$404 \mathrm{E}$

404E:AD A9 CO

4051:29 O8

4053: FO OE

4055:A9 01

4057:8D 7942

405A:AD A8 CO

4050:8D 7A 42

4060:20 8C 40

4063:AD C9 CO

4066:2908

4068:FO OE

406A:A9 02

406C:8D 7942

406F : AD C8 CO

4072:8D 7A 42

4075:20 4F 41

4078:A5 45

407A:40

4078

4078:

4078

4078:80 FF CF

407E:8D 00 C3

4081: $A 030$

4083:8C F8 06

4086:A2 C3

4088:8E F8 07

408B: 60

$408 \mathrm{C}$

$408 \mathrm{C}$

$408 \mathrm{C}$

$408 \mathrm{C}: 8 \mathrm{D} 7 \mathrm{~B}$ O6

408F:8A

4090:48

$4091: 98$

4092:48

4093:20 7B 40

4096: AD 7B 06

4099:C9 OD

409B:DO 4C

409D:A9 20

409F:AE 4D 41

\section{3}

24

25

26

27

28

29

30

31

32

33

34

35

36

37

38

39

40

41

42

43

44

45

46

47

48

LDA \#54

STA CONTROL+SLOT

STA CONTROL+SLOT2

LDA \#105

STA COMMAND+SLOT2

LDA \#START

STA IRQT

STA IRQ2

CLI

JSR SETREGS

JSR $\$ C 809$

LDA \#\$OA

STA $\$ C O B O$

LDA \#\$20

STA \$COB1

LDA \#CUR

LDX HOR1

LDY VER1

JSR OUTPUT

LDX HOR2

LDY VER2

JSR OUTPUT

LDX $\# 00$

LDY $\# 12$

OOP LDA \#SEPR

INX

CPX $\# 80$

BNE SLOOP

RTS

AND \#\$8

BEQ NSLOT

LDA \#\$01

STA FLAG

LDA DATA+SLOT

STA INDATA

JSR DISPLAY

LDA $\# \$ 22$

STA FLAG

LDA DATA+SLOT2

STA INDATA

JSR DISPLA2

SLOT LDA ACC RTI

SETREGS STA \$CFFF

STA $\$ C 300$

LDY $\# \$ 30$

STY NO

LDX \#\$CB

STX MSLOT

RTS

- displar for fIRST DEVICE

TXA

PHA

TYA

PHA

JSR SETREGS

LDA BYTE+3

CMP \#\$OD

BNE VDOUT1

LDA \#SP

LDX HOR1
58 START LDA STATUS+SLOT LOAD STATUS REG OF 1ST SERIAL PORT

STA COMMAND+SLOT

LDA \#<START

- INTERRUPT SERVICE ROUTINE •

LOAD CURSOR TO LOCATION

SET BY HORIZONTAL \& VERTICAL

POINTERS

BRANCH TO OUTPUT ROUTINE

SET INDEX REGS TO

SEPARATE TOP \& BOTTOM OF SCREEN

LOAD SEPR CHARACTER

INCREMENT SEPR COUNTER

CHECK IF END

IF NO BRANCH TO FINISH SEPR

END OF INIT ROUTINE

CHECK IF BUFFER FUL

IF NOT CHECK 2ND SERIAL PORT

SET KEYBOARD FLAG TO 1

GET DATA FROM BUFFER

SAVE INCOMING CHARACTER JUMP TO TOP DISPLAY ROUTINE

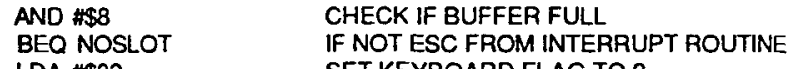

BEQ NOSLOT

CHECK IF BUFFER FULL

NOT ESC FROM INTERRUPT ROUTINE

- SET REgISTERS FOR $80 \mathrm{COL}$ CARO

ISPLAY STA BYTE+3 SAVE ACCUMULATOR

GET DATA FROM BUFFER

SAVE INCOMING CHARACTER JUMP TO BOTTOM DISPLAY ROUTINE RESTORE ACCUMULATOR SAVE X-REG

SAVE Y-REG

SET REGS FOR 80-COL CARD RESTORE ACCUMULATOR

CHECK IF INCOME CHAR = RETURN? IF NO BRANCH VIDEO OUTPUT ROUTINE LOAD NULL CHARACTER TO ACC LOAD HORIZONTAL POINTER 







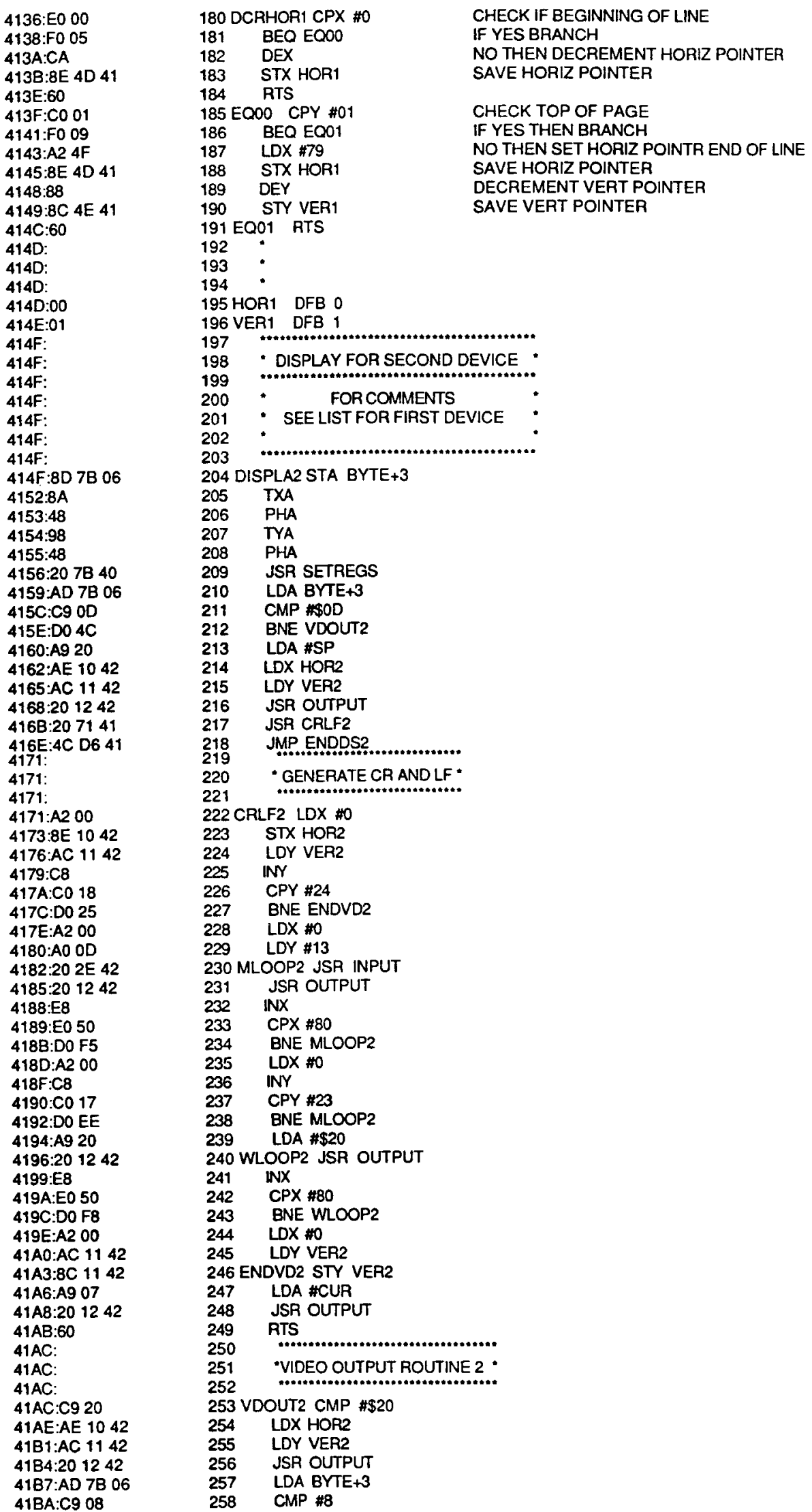




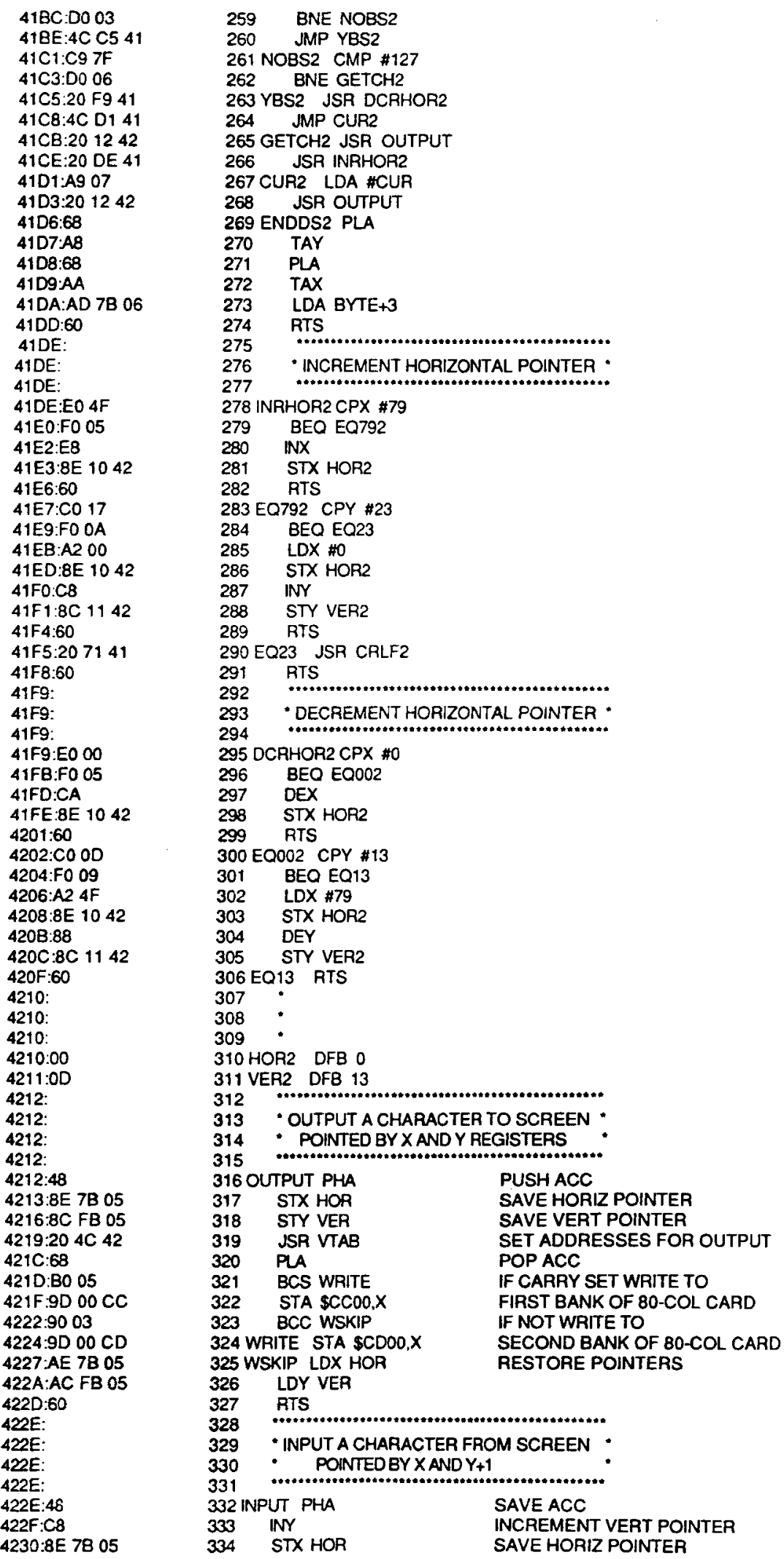




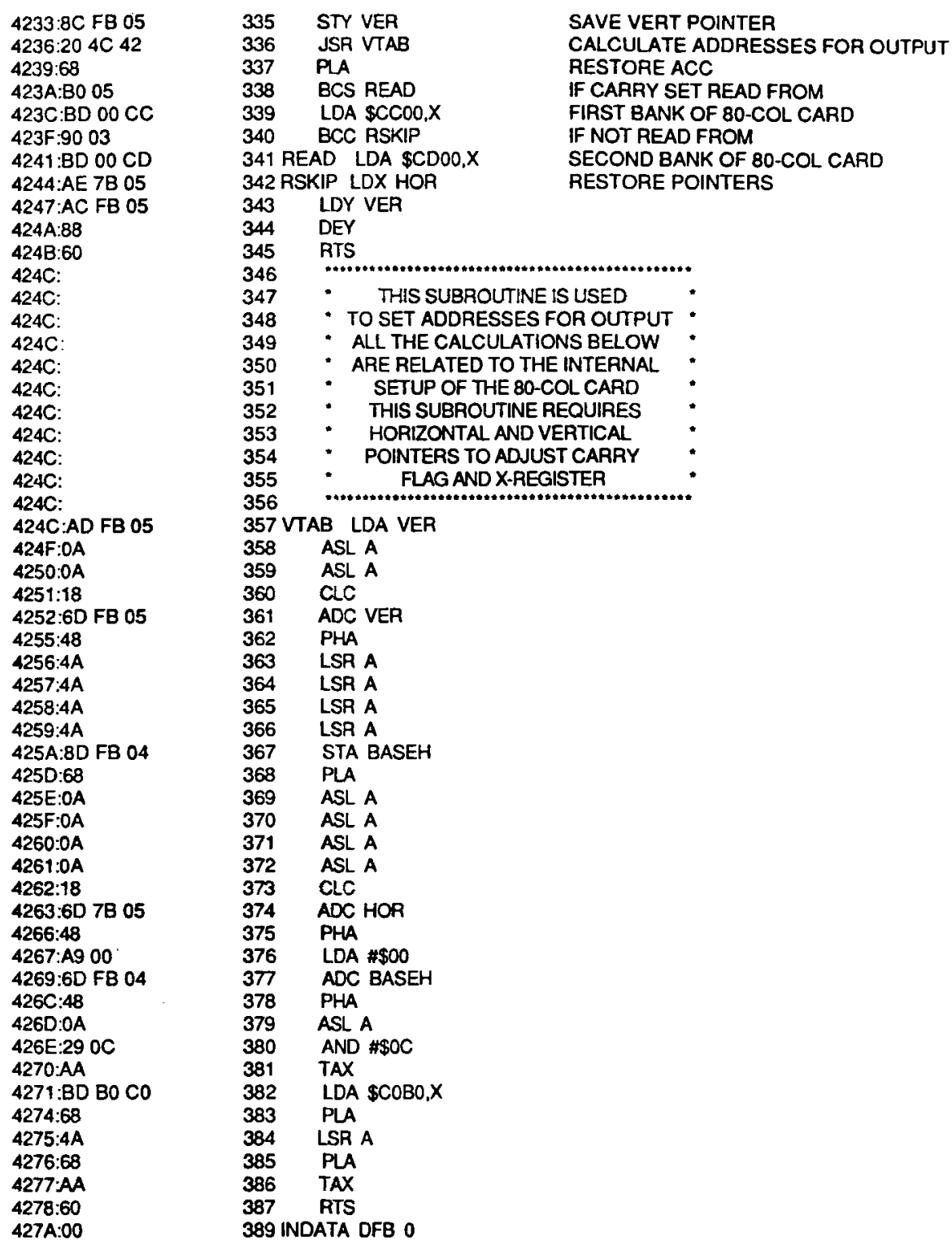

SUCCESSFUL ASSEMBLY: NO ERRORS

\begin{tabular}{|c|c|c|c|}
\hline $\begin{array}{c}45 \text { ACC } \\
\text { CO8B CONTROL }\end{array}$ & $\begin{array}{l}\text { 04FB BASEH } \\
\text { 40AE CRLF1 }\end{array}$ & $\begin{array}{l}0678 \mathrm{BYTE} \\
4171 \mathrm{CRLF2}\end{array}$ & $\begin{array}{l}\text { COBA COMMAND } \\
07 \text { CUR }\end{array}$ \\
\hline 410E CUR1 & 41D1 CUR2 & C08B DATA & 4136 DCRHOR1 \\
\hline 41F9 DCRHOR2 & 414F DISPLA2 & 408C DISPLAY & 4113 ENDDS 1 \\
\hline 41D6 ENDDS2 & 40EO ENDVD1 & 41A3 ENDVD2 & $413 F$ ECOO \\
\hline 4202 EOOO2 & $414 C$ EQ01 & 4132 EQ12 & 420F EQ13 \\
\hline $41 F 5$ EQ23 & 4124 EO79 & 41E7 EQ792 & 4279 FLAG \\
\hline 4108 GETCH & 41CB GETCH2 & 414D HOR1 & 0578 HOA \\
\hline $4210 \mathrm{HOR} 2$ & 427A INDATA & 422E INPUT & 411B INRHOR1 \\
\hline 410E INRHOR2 & 03FE IAQ1 & O3FF IRQ2 & 40BF MLOOP1 \\
\hline 4182 MLOOP2 & 07F8 MSLOT & 40FE NOBS1 & 41C1 NOBS2 \\
\hline 4078 NOSLOT & O6F8 NO & 4063 NSLOT & 4212 OUTPUT \\
\hline 4241 READ & 4244 RSKIP & 02 SEPR & 407B SETREGS \\
\hline 404E START & C089 STATUS & 40E9 VDOUT1 & 41AC VDOUT? \\
\hline 05FB VER & 414E VER1 & 4211 VER2 & $424 C \vee T A B$ \\
\hline & 4196 WLOOP2 & 4224 WRITE & 4227 WSKIP \\
\hline
\end{tabular}




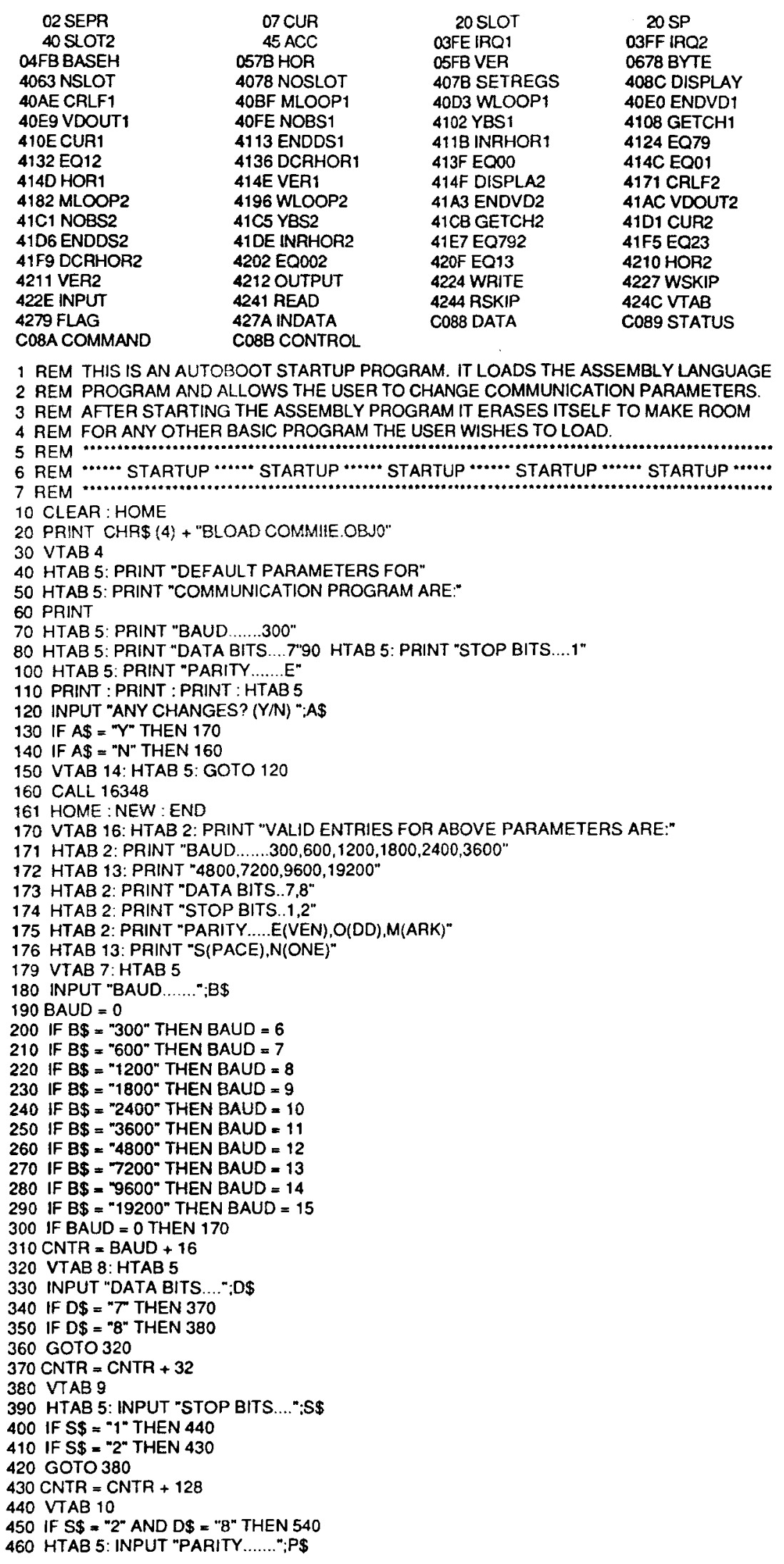




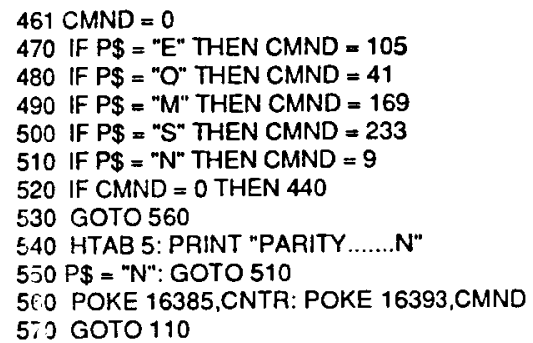

1 FEM THIS IS AN EXAMPLE OF A BASIC PROGRAM THAT CAN BE RUN SIMULTANEOUSLY 2 F $\equiv M$ WITH THE ASSEMBLY PROGRAM. IT SHOULD BE LOADED AND RUN AFTER THE

3 REM STARTUP PROGRAM. IT DISPLAYS THE CURRENT TIME AND DATE AND READS THE

4 REM DATA POKED BY THE ASSEMBLY PROGRAM AT LOCATIONS 17017 (KEYBOARD)

5 REM AND 17018 (ASCII CHARACTER)

6 REM

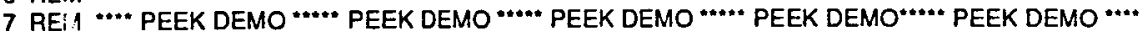

8 REM

15 SLOT $=5$

$20 \mathrm{D} \$=$ CHRS (4)

25 PRINT D\$;"NOMONI,O,C"

30 HOME

34 REM READ THE CLOCK CARD (MOUNTAIN HARDWARE OR WESTSIDE) IN SLOT 5

40 PRINT DS;"IN\#";SLOT

50 PRINT D\$;"PR\#";SLOT

60 VTAB 23

70 INPUT * - TS

80 PRINT DS:"IN\#O"

90 PRINT DS;"PR\#0"

100 VTAB 12

105 REM DISPLAY CURRENT DATE \& TIME

110 PRINT T\$

112 VTAB 13: CALL - 868

115 REM DETERMINE \& DISPLAY LAST KEYBOARD TO SEND MESSAGE (1 OR 2)

116 REM DETERMINE \& DISPLAY LAST CHARACTER RECEIVED (0-255)

120 PRINT PEEK (17017), PEEK (17018)

125 REM TO DISPLAY ACTUAL CHARACTER INSTEAD OF DECIMAL EQUIVALENT USE CHR\$

126 PRINT PEEK (17017), CHR\$(PEEK(17018))

130 GOTO 40

140 END

(Manuscript received July 11, 1985;

revision accepted for publication October $28,1985$. 